\title{
BMJ Open Patterns and co-occurrence of risk factors for hepatocellular carcinoma in four Asian American communities: a cross-sectional study
}

Susan L Stewart, ${ }^{1}$ Julie HT Dang, ${ }^{2}$ Natalie J Török, ${ }^{3}$ Moon S Chen ${ }^{2}$

To cite: Stewart SL, Dang JHT, Török NJ, et al. Patterns and co-occurrence of risk factors for hepatocellular carcinoma in four Asian American communities: a cross-sectional study. BMJ Open 2019:9:e026409. doi:10.1136/ bmjopen-2018-026409

- Prepublication history for this paper is available online. To view these files, please visit the journal online (http://dx.doi org/10.1136/bmjopen-2018026409).

Received 31 August 2018 Revised 23 May 2019 Accepted 3 June 2019

Check for updates

(C) Author(s) (or their employer(s)) 2019. Re-use permitted under CC BY-NC. No commercial re-use. See rights and permissions. Published by BMJ.

${ }^{1}$ Public Health Sciences, University of California Davis School of Medicine, Sacramento, California, USA

${ }^{2}$ UC Davis Comprehensive Cancer Center, University of California Davis School of Medicine, Sacramento, California, USA

${ }^{3}$ Division of Gastroenterology \& Hepatology, Department of Medicine, Stanford University, Stanford, California, USA

Correspondence to Dr Susan L Stewart; sIstewart@ucdavis.edu

\section{ABSTRACT}

Objectives To investigate risk factor patterns and the simultaneous occurrence of multiple risk factors in the viral, metabolic and lifestyle domains among Asian Americans, who have had the highest mortality rates from hepatocellular carcinoma (HCC).

Setting Sacramento County, California, USA.

Participants Eligible participants were county residents ages 18 and older who had not been screened for chronic hepatitis $B$ virus (HBV) and were born in a CDC-defined endemic area or whose parent was born in that area. Of 1004 enrolled, 917 were foreign-born Chinese (130 women, 94 men), Hmong (133 women, 75 men), Korean (178 women, 90 men) or Vietnamese (136 women, 81 men) with complete risk factor data.

Primary and secondary outcome measures We tested participants for HBV and chronic hepatitis C virus (HCV); measured haemoglobin A1c and waist circumference; and recorded self-reported history of diabetes, hypertension, alcohol use and smoking status. We identified risk factor patterns using cluster analysis and estimated genderspecific age-standardised prevalence rates.

Results We identified four patterns: (1) viral (chronic HBV or HCV); (2) lifestyle (current smoker or alcohol user, no viral); (3) metabolic ( $\geq 2$ metabolic, no lifestyle or viral); and (4) lower risk ( $\leq 1$ metabolic, no lifestyle or viral). Vietnamese men $(16.3 \%, 95 \% \mathrm{Cl} 7.4 \%$ to $25.3 \%)$ and Hmong women $(15.1 \%, 95 \% \mathrm{Cl} 7.8 \%$ to $22.5 \%)$ had the highest viral pattern prevalence. Hmong women had the highest metabolic $(37.8 \%, 95 \% \mathrm{Cl} 29.8 \%$ to $45.9 \%$ ), and Vietnamese men the highest lifestyle (70.4\%, 95\% Cl 59.1\% to $81.7 \%$ ) pattern prevalence. In multiple domains, Hmong men and women were most likely to have viral+metabolic risk factors (men: $14.4 \%$, $95 \% \mathrm{Cl} 6.0 \%$ to $22.7 \%$; women: $11.9 \%, 95 \% \mathrm{Cl} 5.6 \%$ to $18.3 \%$ ); Vietnamese men were most likely to have lifestyle+viral $(10.7 \%, 95 \% \mathrm{Cl} 2.7 \%$ to $18.8 \%)$, and lifestyle+metabolic but not viral $(46.4 \%, 95 \% \mathrm{Cl} 34.4 \%$ to $58.5 \%$ ) risk factors.

Conclusions Efforts to reduce HCC must comprehensively address multiple risk factors.

Trial registration number NCT02596438.

\section{BACKGROUND}

Hepatocellular carcinoma (HCC), the primary form of liver cancer, is the world's

\section{Strengths and limitations of this study}

- This was a large community-based study that collected primary data on the prevalence of several viral, metabolic and lifestyle risk factors for hepatocellular carcinoma in four Asian American ethnic groups.

- Hepatitis B virus (HBV), hepatitis C virus, haemoglobin $A 1 C$, waist circumference, height and weight were measured directly, but history of diabetes, hypertension, smoking and alcohol use were self-reported.

- Liver damage was not assessed in these participants; however, the selected risk factors are well established.

- This was a convenience sample of people born in countries where HBV is endemic and therefore potentially subject to selection bias.

second leading cause of cancer deaths. ${ }^{1}$ HCC disproportionately affects all populations of colour with Asian/Pacific Islanders having experienced the highest mortality rates. ${ }^{2}$

Worldwide and among Asians, the principal acquired risk factors for HCC have been viral: chronic hepatitis B virus (HBV) and hepatitis $\mathrm{C}$ virus (HCV). Globally, liver cancer deaths have been attributed to HBV (37\%), HCV $(42 \%)$, alcohol $(11 \%)$ and all other causes $(10 \%){ }^{3}$

Non-alcoholic steatohepatitis (NASH) with its associated conditions obesity and type 2 diabetes is now reported to be the leading cause of HCC in places with historically low HCC incidence. ${ }^{4}$ NASH, metabolic syndrome,${ }^{56}$ high blood glucose levels, high body mass index (BMI) ${ }^{7}$ and obesity ${ }^{8}$ are increasingly recognised as prominent and potentially independent risk factors for HCC. Lifestyle factors, for example, heavy alcohol consumption ${ }^{79}$ and smoking, ${ }^{10}$ also increase risk. Among these factors, the relative risk (RR) of HCC is highest for HBV/ HCV (RR=22-60), followed by excessive 
alcohol $(\mathrm{RR}=7.5)$, metabolic disorders $(\mathrm{RR}=3.8)$ and smoking $(\mathrm{RR}=1.5)$, with differences in risk factor prevalence responsible for much of the demographic variation in liver cancer incidence. ${ }^{11}$

The Centers for Disease Control and Prevention (CDC) has recommended a multicomponent approach to address concurrent risk factors in the population, calling for collaborations between communities and healthcare providers to reduce the burden of chronic disease. ${ }^{12} \mathrm{We}$ previously documented the prevalence of $\mathrm{HBV}^{13}$ and metabolic risk factors ${ }^{14}$ in a sample of Asian Americans residing in Sacramento County, California. The purpose of this paper is to investigate risk factor patterns and the simultaneous occurrence of multiple risk factors in the viral, metabolic and lifestyle domains.

\section{METHODS}

\section{Study design}

The goal of the Thousand Asian Americans Study (TAAS), conducted in 2012-2013, was to screen 1000 Sacramento County, California, Asian American community adult residents for HBV, the principal risk factor for HCC among Asian Americans. ${ }^{2}$ Ethics approval was obtained.

\section{Participants}

Eligible participants were residents of Sacramento County, ages 18 and older who had not been screened for HBV and were born in a CDC-defined endemic area or whose parent was born in that area. ${ }^{4}$ These countries included China, Laos, Thailand, Korea, and Vietnam. We collaborated with community partners who were serving Chinese, Hmong, Korean, and Vietnamese to conduct 28 community screening events as previously described. ${ }^{13}$ All study materials were translated by the UC Davis Interpreting and Translation Services and reviewed by our community partners for cultural appropriateness. Our community partners also provided interpretation during screening events. Clients completing the screening received a $\$ 10$ gift card.

\section{Patient and public involvement}

Several community organisations were involved in planning this research, including two UC Davis sponsored student-run clinics, the Paul Hom Asian Clinic and the Vietnamese Cancer Awareness Research and Education Society, which provide medical care primarily to Chinese and Vietnamese patients, respectively, and the Hmong Women's Heritage Association, a community-based organisation serving the local Hmong population. These community partners and a Korean community leader, who convened the Shalom Korean cancer support group, as well as the California Northstate University Cancer Awareness, Research and Education student organisation, were also centrally involved in recruiting participants and conducting the study. ${ }^{13}$ Study results will be made available at www.ucdmc.ucdavis.edu/cancer/research/ programs/aancart/projects.html.

\section{Data collection}

After providing informed consent, participants filled out a brief intake form including age, ethnicity, country of birth, gender, year of arrival in the USA, smoking history, current alcohol use, history of diabetes and other medical conditions, and family history of liver cancer. Research staff measured the participant's height (inches), weight (pounds) and waist circumference (inches), and a phlebotomist drew blood for diagnostic testing for hepatitis B surface antigen (HBsAg), hepatitis B surface antibody (anti-HBs), total hepatitis B core antibody (anti-HBc), total hepatitis $\mathrm{C} \mathrm{Ab}$, and the haemoglobin A1c (HbAlc) test. All samples were processed by the UC Davis Department of Pathology and Laboratory Medicine.

\section{Measures}

Percent of life spent in the USA was determined by subtracting the self-reported year of arrival to the USA from the current year, dividing by age and multiplying by 100 . Body mass index (BMI) in $\mathrm{kg} / \mathrm{m}^{2}$ was computed as weight (lb) $/[\text { height (in) }]^{2} \times 703$. BMI was classified with respect to the standard cut-point for elevated risk of diabetes (BMI $\geq 25)$ and the Asian cut-point (BMI $\geq 23) .{ }^{15}$ From a literature review, we identified seven principal acquired risk factors for HCC in three domains ${ }^{4-11 ~ 16-18}$ : HBV and HCV in the viral domain; high glucose (HbA1c $\geq 5.7 \%$ or self-reported diabetes), large waist ( $\geq 32$ inches for women, $\geq 35$ inches for men) ${ }^{19}$ and hypertension (self-reported) in the metabolic domain; and alcohol use in the past 30 days and being a current smoker in the lifestyle domain.

\section{Analysis}

Foreign-born Chinese, Hmong, Korean and Vietnamese participants with complete risk factor data were included in the analysis. We compared the four ethnic groups with respect to age, percent of life in the USA, family history of liver cancer and BMI among men and women separately using analysis of variance to compare means and $\chi^{2}$ tests to compare proportions (table 1). We then identified risk factor patterns by performing principal component analysis on variables denoting presence or absence of the risk factors (HBV and/or HCV, high glucose, large waist, hypertension, alcohol and smoking), and performing agglomerative hierarchical cluster analysis on the principal component scores with eigenvalues $>1$ using Ward's minimum variance method. ${ }^{20}$ We estimated the prevalence of HCC risk factors in each domain (viral, metabolic and lifestyle), risk factor patterns and co-occurring risk factors in multiple domains within these patterns, by gender and ethnicity. Estimates with $95 \%$ CI were age standardised to the Sacramento County 2010 population distribution $^{21}$ using the following weights: age 18-44: 0.51,

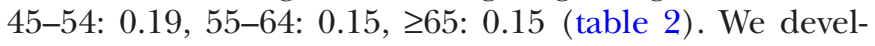
oped two multinomial models of risk factor patterns using logistic regression with generalised logits. Both models included gender, ethnicity, age, percent of life in the USA and gender-ethnicity, gender-age and gender-life in 
Table 1 Characteristics of a sample of foreign-born Asian American residents of Sacramento County, California, 2012-2013 $(n=917)$

\begin{tabular}{|c|c|c|c|c|c|}
\hline & Chinese & Hmong & Korean & Vietnamese & All \\
\hline & $(n=130)$ & $(n=133)$ & $(n=178)$ & $(n=136)$ & $(n=577)$ \\
\hline Women & $\mathrm{n}(\%)$ & $\mathrm{n}(\%)$ & $\mathrm{n}(\%)$ & $\mathrm{n}(\%)$ & $\mathrm{n}(\%)$ \\
\hline \multicolumn{6}{|l|}{ Age (years) } \\
\hline $18-44$ & $24(18)$ & $32(24)$ & $25(14)$ & $32(24)$ & $113(20)$ \\
\hline $45-54$ & $42(32)$ & $36(27)$ & $47(26)$ & $41(30)$ & $166(29)$ \\
\hline Mean (SD) & $51.7(11.5)$ & $52.3(13.4)$ & $58.9(14.0)$ & $51.7(11.9)$ & $54.0(13.2)$ \\
\hline Median (min-max) & $54(18-80)$ & $54(19-89)$ & $59(21-91)$ & $54(19-82)$ & $55(18-91)$ \\
\hline \multicolumn{6}{|l|}{ Life in USA (\%) } \\
\hline$<25$ & $48(40)$ & $20(15)$ & $40(23)$ & $53(40)$ & $161(29)$ \\
\hline Median (min-max) & $30.5(1.7-95.5)$ & $51.6(9.1-94.4)$ & $44.2(0-100)$ & $31.0(0-80.0)$ & $39.2(0-100)$ \\
\hline Family history of liver cancer & $4(3)$ & $1(1)$ & $22(12)$ & $16(12)$ & $43(7)$ \\
\hline \multicolumn{6}{|l|}{ BMI $\left(\mathrm{kg} / \mathrm{m}^{2}\right)$} \\
\hline$<23$ & $70(54)$ & $12(9)$ & $78(44)$ & $68(51)$ & $228(40)$ \\
\hline $23-25$ & $26(20)$ & $18(14)$ & $41(23)$ & $26(19)$ & $111(19)$ \\
\hline$\geq 25$ & $34(26)$ & $103(77)$ & $59(33)$ & $40(30)$ & $236(41)$ \\
\hline Mean (SD) & $23.1(3.5)$ & $27.9(3.9)$ & $23.6(3.1)$ & $23.2(3.4)$ & $24.4(4.0)$ \\
\hline \multirow[t]{2}{*}{ Median (min-max) } & $22.6(14.8-34.9)$ & $27.6(20.3-39.9)$ & $23.5(16.4-33.3)$ & $22.8(17.0-35.9)$ & $23.8(14.8-39.9)$ \\
\hline & Chinese & Hmong & Korean & Vietnamese & All \\
\hline$\geq 65$ & $10(11)$ & $9(12)$ & $35(39)$ & $11(14)$ & $65(19)$ \\
\hline Mean (SD) & $53.7(10.9)$ & $50.5(15.5)$ & $60.0(13.2)$ & $51.9(13.3)$ & $54.2(13.6)$ \\
\hline Median (min-max) & $55.5(22-76)$ & $53(18-81)$ & $58.5(20-92)$ & $55(21-83)$ & 55.5 (18-92) \\
\hline \multicolumn{6}{|l|}{ Life in USA (\%) } \\
\hline$<25$ & $38(43)$ & $6(8)$ & $19(22)$ & $22(28)$ & $85(26)$ \\
\hline $25-50$ & $23(26)$ & $25(34)$ & $39(44)$ & $27(34)$ & $114(35)$ \\
\hline$\geq 50$ & $27(31)$ & $43(58)$ & $30(34)$ & $31(39)$ & $131(40)$ \\
\hline Mean (SD) & $33.4(21.9)$ & $51.6(19.9)$ & $42.0(19.1)$ & $39.6(22.4)$ & $41.3(21.7)$ \\
\hline Median (min-max) & $28.6(0-97.1)$ & $52.0(10.7-100)$ & $44.2(0-100)$ & $40.8(0-94.1)$ & $42.6(0-100)$ \\
\hline Family history of liver cancer & $4(4)$ & $1(1)$ & $7(8)$ & $6(7)$ & $18(5)$ \\
\hline \multicolumn{6}{|l|}{ BMI $\left(\mathrm{kg} / \mathrm{m}^{2}\right)$} \\
\hline$<23$ & $38(40)$ & $8(11)$ & $30(33)$ & $32(40)$ & $108(32)$ \\
\hline $23-25$ & $29(31)$ & $10(14)$ & $23(26)$ & $19(23)$ & $81(24)$ \\
\hline$\geq 25$ & $27(29)$ & $56(76)$ & $37(41)$ & $30(37)$ & $150(44)$ \\
\hline Mean (SD) & $23.7(3.0)$ & $27.1(3.8)$ & $24.4(3.4)$ & $23.6(3.0)$ & $24.6(3.6)$ \\
\hline Median (min-max) & $23.6(17.1-35.1)$ & $27.1(19.3-39.9)$ & $24.2(16.1-36.4)$ & 23.7 (16.9-29.1) & $24.4(16.1-39.9)$ \\
\hline
\end{tabular}

Missing values: life in USA ( $n=33)$, BMI $(n=3)$. Note, gender-specific ethnic differences in proportions were assessed using chi-square tests, and differences in means were assessed using analysis of variance (ANOVA), all $p<0.0001$, except family history of liver cancer in men $(p=0.22)$. 
Table 2 Prevalence of hepatocellular carcinoma risk factors in a sample of foreign-born Asian American residents of Sacramento County, California, 2012-2013 ( $n=917)$

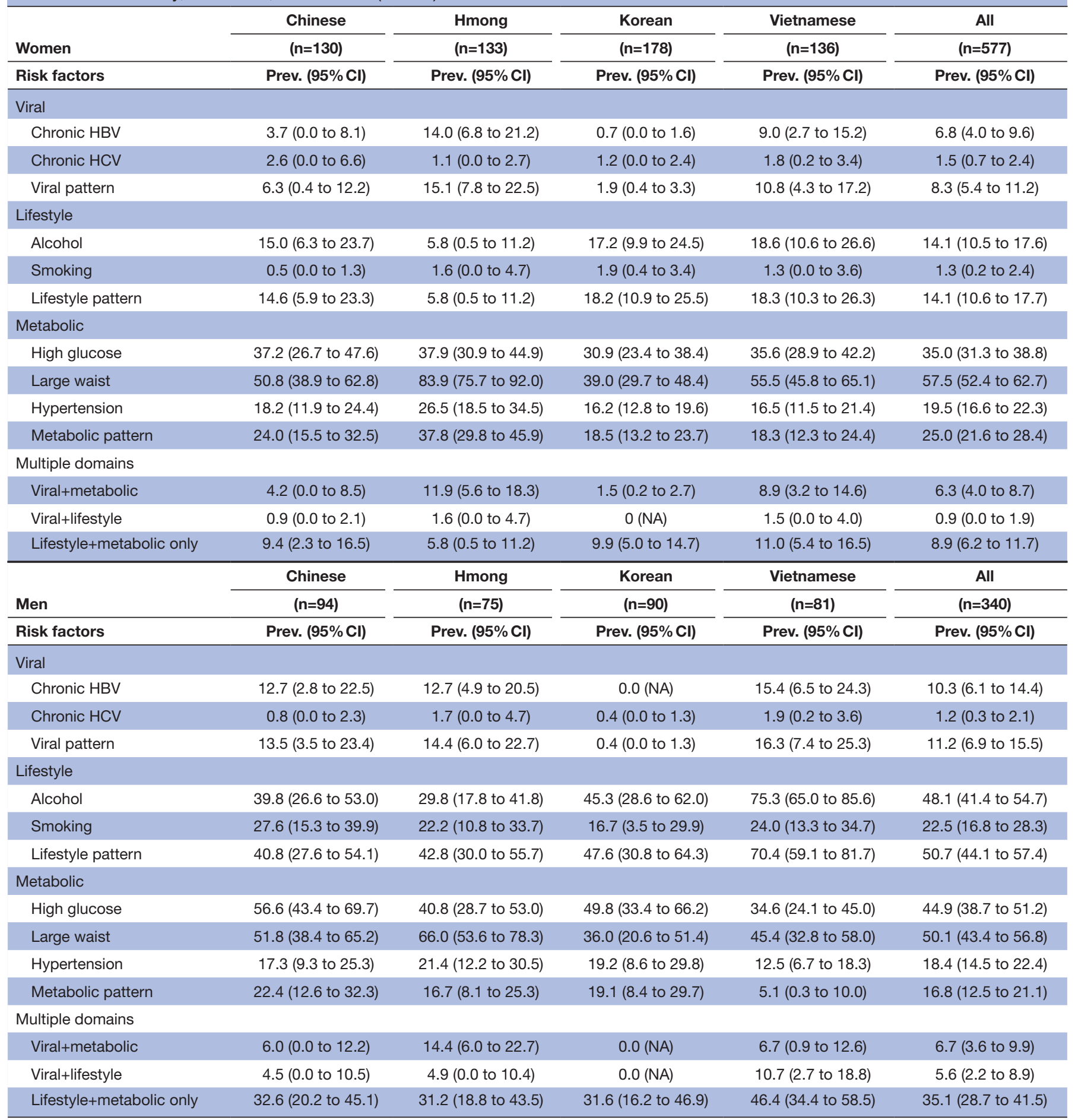

Notes: Estimates of prevalence with 95\% confidence intervals $(\mathrm{Cl})$ are age standardised to the Sacramento County 2010 population distribution: 18-44: 0.51, 45-54: 0.19, 55-64: 0.15, $\geq 65$ : 0.15; HBV=hepatitis B virus; $\mathrm{HCV}=$ hepatitis $\mathrm{C}$ virus; RF=risk factor; NA=not applicable; high glucose: haemoglobin $\mathrm{A} 1 \mathrm{c} \geq 5.7 \%$ or self-reported diabetes; large waist: $\geq 32$ inches (women), $\geq 35$ inches (men); hypertension: self-reported; alcohol: used in past 30 days; smoking: current smoker. Risk factor (RF) patterns: viral-chronic hepatitis B or C; lifestyle-current smoker or alcohol user, no viral RF; metabolic - 2-3 metabolic RF (high glucose, large waist, hypertension), no viral or lifestyle RF; lower risk-0-1 metabolic RF, no viral or lifestyle RF.

USA interactions, enabling us to estimate gender-specific OR with $95 \% \mathrm{CI}$ as well as a main effect for gender. Variables were included in the models based on clinical significance; age was included also as a potential confounder of the relationship between the other independent variables and the risk factor patterns. Because BMI is associated with metabolic syndrome and its components, ${ }^{22}$ and so may explain some of the relationship between demographic 
characteristics and risk factor patterns, a second model included BMI and a gender-BMI interaction (table 3). Observations with missing data were excluded from analyses where applicable. Statistical significance was assessed at the 0.05 level (two-sided).

\section{Results}

Of the 1004 participants enrolled in TAAS, 965 were foreign-born Chinese, Hmong, Korean or Vietnamese, with 917 of the 965 having complete risk factor data. Table 1 shows the demographic characteristics of our sample. On average, Hmong had spent the largest proportion of their life in the USA and had the highest BMIs. Koreans were the oldest; Korean and Vietnamese women were most likely to report a family history of liver cancer.

Four hierarchical risk factor patterns were identified: (1) viral (has chronic HBV or HCV, $\mathrm{n}=86$ ); (2) lifestyle (current smoker or alcohol user, no viral risk factors, $\mathrm{n}=246$ ); (3) metabolic ( $\geq 2$ metabolic risk factors, no lifestyle or viral risk factors, $n=283$ ); and (4) lower risk $(\leq 1$ metabolic risk factor, no lifestyle or viral risk factors, $n=302$ ). Although the risk factor patterns were mutually exclusive, the viral and lifestyle patterns allowed for risk factors in more than one domain: people with the viral pattern may also have had lifestyle and/or metabolic risk factors, and those with the lifestyle pattern may also have had metabolic risk factors.

Table 2 shows the prevalence of HCC risk factors by gender and ethnicity. Among women, the metabolic pattern was most common $(25.0 \%, 95 \%$ CI $21.6 \%$ to $28.4 \%)$, followed by the lifestyle $(14.1 \%, 95 \%$ CI $10.6 \%$ to $17.7 \%)$ and viral $(8.3 \%, 95 \%$ CI $5.4 \%$ to $11.2 \%)$ patterns. Among men, the lifestyle pattern was most common $(50.7 \%, 95 \%$ CI $44.1 \%$ to $57.4 \%)$, followed by the metabolic $(16.8 \%, 95 \%$ CI $12.5 \%$ to $21.1 \%)$ and viral $(11.2 \%$, 95\% CI $6.9 \%$ to $15.5 \%$ ) patterns. Lifestyle and metabolic with no viral risk factors was the most common multiple domain combination for both women $(8.9 \%, 95 \%$ CI $6.2 \%$ to $11.7 \%)$ and men $(35.1 \%, 95 \%$ CI $28.7 \%$ to $41.5 \%)$.

The prevalence of risk factor patterns among Chinese women and men was similar to that of the overall sample. The prevalence of the patterns among Chinese women was: metabolic $24.0 \%$ (95\% CI $15.5 \%$ to $32.5 \%$ ), lifestyle $14.6 \%$ (95\% CI $5.9 \%$ to $23.3 \%$ ) and viral $6.3 \%$ (95\% CI $0.4 \%$ to $12.2 \%)$. The prevalence of the patterns among Chinese men was: lifestyle $40.8 \%$ (95\% CI $27.6 \%$ to $54.1 \%$ ), metabolic $22.4 \%$ (95\% CI $12.6 \%$ to $32.3 \%$ ) and viral $13.5 \%$ (95\% CI $3.5 \%$ to $23.4 \%$ ). The prevalence of both lifestyle and metabolic risk factors with no viral was 9.4\% (95\% CI $2.3 \%$ to $16.5 \%$ ) for women and $32.6 \%$ (95\% CI $20.2 \%$ to $45.1 \%$ ) for men.

Hmong women had the highest metabolic pattern prevalence $(37.8 \%, 95 \%$ CI $29.8 \%$ to $45.9 \%)$ and the highest viral pattern prevalence among women $(15.1 \%, 95 \% \mathrm{CI}$ $7.8 \%$ to $22.5 \%)$, but the lowest lifestyle pattern prevalence $(5.8 \%, 95 \%$ CI $0.5 \%$ to $11.2 \%)$. Hmong men had risk factor patterns similar in prevalence to those of the overall sample: lifestyle $42.8 \%$ (95\% CI $30.0 \%$ to $55.7 \%$ ), metabolic $16.7 \%$ (95\% CI $8.1 \%$ to $25.3 \%)$ and viral $14.4 \%$ (95\% CI $6.0 \%$ to $22.7 \%$ ), as well as both lifestyle and metabolic risk factors with no viral $31.2 \%$ (95\% CI $18.8 \%$ to $43.5 \%)$ ). Hmong men and women were the most likely to have both viral and metabolic risk factors (men: $14.4 \%, 95 \%$ CI $6.0 \%$ to $22.7 \%$; women: $11.9 \%$, $95 \%$ CI $5.6 \%$ to $18.3 \%$ ).

Koreans had the lowest viral risk pattern prevalence (men: $0.4 \%, 95 \%$ CI $0.0 \%$ to $1.3 \%$; women: $1.9 \%, 95 \%$ CI $0.4 \%$ to $3.3 \%$ ). However, the prevalence of metabolic and lifestyle risk factor patterns was similar to that of the overall sample. Among Korean women the prevalence of the metabolic pattern was $18.5 \%$ (95\% CI $13.2 \%$ to $23.7 \%$ ) and the lifestyle pattern $18.2 \%$ (95\% CI $10.9 \%$ to $25.5 \%)$. Among Korean men, the prevalence of the lifestyle pattern was $47.6 \%$ (95\% CI $30.8 \%$ to $64.3 \%$ ) and the metabolic pattern $19.1 \%$ (95\% CI $8.4 \%$ to $29.7 \%$ ). The prevalence of both lifestyle and metabolic risk factors but no viral was $9.9 \%$ (95\% CI $5.0 \%$ to $14.7 \%$ ) for women and $31.6 \%$ (95\% CI $16.2 \%$ to $46.9 \%$ ) for men.

Vietnamese men had the highest viral $(16.3 \%, 95 \%$ CI $7.4 \%$ to $25.3 \%$ ) and lifestyle pattern prevalence $(70.4 \%$, $95 \%$ CI $59.1 \%$ to $81.7 \%$ ), and were most likely to have lifestyle risk factors along with viral $(10.7 \%, 95 \%$ CI $2.7 \%$ to $18.8 \%)$ or metabolic and no viral $(46.4 \%, 95 \%$ CI $34.4 \%$ to $58.5 \%$ ) risk factors. However, they had the lowest metabolic pattern prevalence $(5.1 \%, 95 \%$ CI $0.3 \%$ to $10.0 \%)$. In contrast, risk factor patterns among Vietnamese women were similar in prevalence to those of the overall sample: metabolic $18.3 \%$ (95\% CI $12.3 \%$ to $24.4 \%$ ), lifestyle $18.3 \%$ (95\% CI $10.3 \%$ to $26.3 \%$ ) and viral $10.8 \%$ (95\% CI $4.3 \%$ to $17.2 \%$ ), as well as both lifestyle and metabolic risk factors with no viral $11.0 \%$ (95\% CI $5.4 \%$ to $16.5 \%$ ).

Men and women differed significantly with respect to the association between demographic characteristics and the viral, lifestyle and metabolic risk patterns vs. the lower risk pattern (table 3). However, the association between BMI and risk factor pattern did not differ by gender $(\mathrm{p}=0.82)$. The addition of BMI to the model did not change the magnitude of associations substantively, except as noted below.

The viral risk pattern was more common among older women (age $\geq 65$ vs $18-44$ : $\mathrm{OR}=13$, 95\% CI 3.9 to 41 , $\mathrm{p}<0.0001)$ and less common among men who had lived at least half their life in the USA ( $\mathrm{OR}=0.3,95 \%$ CI 0.1 to 0.9 , $\mathrm{p}=0.028$ ). The odds of having the viral risk pattern versus the lower risk pattern increased with BMI among both women ( $\geq 25 \mathrm{vs}<23$ : OR=3.1, 95\% CI 1.2 to $7.6, \mathrm{p}=0.015$ ) and men ( $\geq 25 \mathrm{vs}<23$ : OR=3.7, 95\% CI 1.2 to $11, \mathrm{p}=0.021)$. After adjustment for BMI, Hmong women no longer had increased odds of having the viral pattern, but Vietnamese men remained more likely and Korean men less likely than Chinese men to have this pattern.

Men were more much likely than women to have the lifestyle pattern versus the lower risk pattern $(\mathrm{OR}=6.9$, 95\% CI 4.2 to $11, \mathrm{p}<0.0001)$. Among women, the lifestyle pattern was more common among those who were older (age $\geq 65$ vs $18-44$ : OR=5.1, 95\% CI 1.9 to $13, \mathrm{p}=0.001$ ) or 


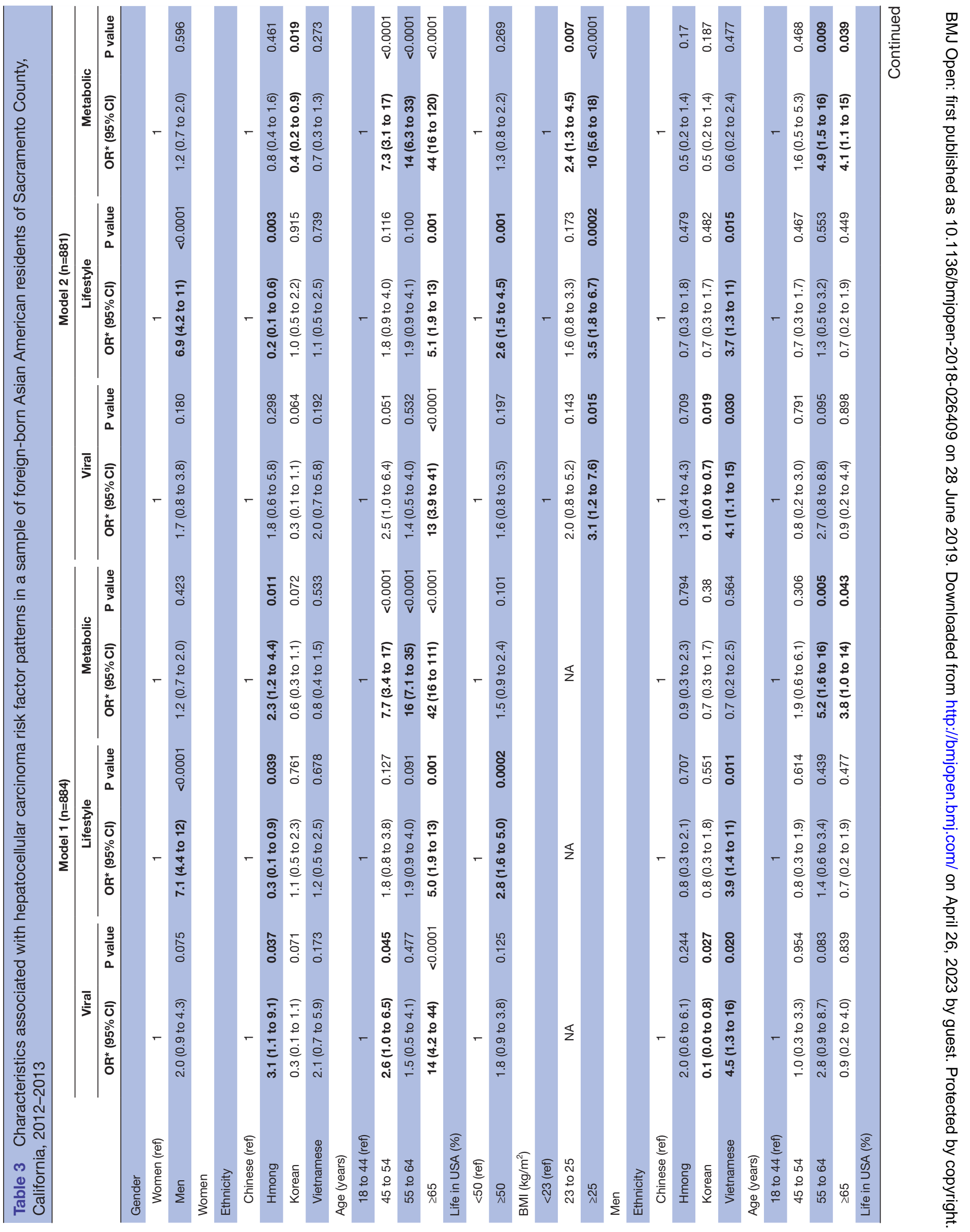


had higher BMI ( $\geq 25$ vs $<23$ : OR=3.5 (1.8-6.7, p=0.0002). Women who had lived half or more of their life in the USA were more likely $(\mathrm{OR}=2.6,95 \%$ CI 1.5 to $4.5, \mathrm{p}=0.001)$, whereas such men were less likely $(\mathrm{OR}=0.5,95 \%$ CI 0.2 to $1.0, \mathrm{p}=0.035$ ), to have the lifestyle pattern. Hmong women were less likely and Vietnamese men were more likely than their Chinese counterparts to have the lifestyle pattern.

Among women the odds of having the metabolic pattern versus the lower risk pattern increased greatly with age (55-64 vs 18-44: OR=14, 95\% CI 6.3 to $33, \mathrm{p}<0.0001 ; \geq 65$ vs 18-44: $\mathrm{OR}=44,95 \%$ CI 16 to $120, \mathrm{p}<0.0001$ ), whereas among men the magnitude of association was considerably smaller (55-64 vs 18-44: OR $=4.9,95 \%$ CI 1.5 to $16, \mathrm{p}=0.009$; $\geq 65$ vs $18-44: \mathrm{OR}=4.1,95 \%$ CI 1.1 to 15 , $\mathrm{P}=0.039$ ). BMI was strongly associated with the metabolic pattern in both women ( $\geq 25$ vs $<23$ : OR $=10,95 \%$ CI 5.6 to $18, \mathrm{p}<0.0001)$ and men $(\geq 25 \mathrm{vs}<23$ : OR=6.5, 95\% CI 2.5 to $17, \mathrm{p}=0.0001$ ). After adjustment for BMI, Hmong women no longer had increased odds and Korean women had decreased odds of having the metabolic pattern compared with Chinese women.

\section{DISCUSSION}

The foreign-born can be considered a vulnerable population in transition, at increased risk of disease due to factors acquired in their country of residence as well as their country of origin. A retrospective cohort study of Asian American HCC patients also found a high prevalence of metabolic risk factors, which increased over time from 1988 to 2015. ${ }^{23}$ In a cohort of North American HBV patients, diabetes was more prevalent than in the general population and was associated with other metabolic risk factors and liver damage. ${ }^{24}$

The consequences of having multiple risk factors can be serious, including synergistic effects of alcohol with obesity, ${ }^{7}$ diabetes ${ }^{9}$ and viral hepatitis. ${ }^{9}$ Among patients with chronic HBV, metabolic risk factors can accelerate the progression of liver disease, producing a synergistic effect on liver damage. ${ }^{25}$ In one study, $40 \%$ of HBV-infected patients had fatty liver, which was associated with metabolic risk factors, cirrhosis and HCC development. ${ }^{26}$ Another study found that diabetes had a synergistic effect on HCC risk among patients with chronic HCV and among alcohol abusers, and that alcohol abuse in HCV patients was associated with younger age at HCC diagnosis. $^{27}$

As expected, HBV was much more common than HCV among Chinese, Hmong and Vietnamese participants. ${ }^{28}$ Our HBV prevalence estimates for Vietnamese and Hmong women and men and Chinese men were consistent with a meta-analysis of HBV prevalence in foreignborn USA residents, which reported estimates of $12.25 \%$, $13.61 \%, 5.26 \%$ and $12.48 \%$ for those born in China, Laos, Korea and Vietnam, respectively. ${ }^{17}$ However, our estimates for Chinese and Korean women were lower, and we found no cases of $\mathrm{HBV}$ among Korean men. It is possible 
that our outreach to the Korean community ${ }^{13}$ reached a segment of the population with lower prevalence of HBV.

The lifestyle pattern was much more common in men than in women in all ethnic groups. We also found that living $\geq 50 \%$ of life in the USA was associated with increased odds of the lifestyle pattern for women, but decreased odds for men. Among Asian Americans acculturation has opposite gender-specific effects on smoking, ${ }^{29}$ and alcohol consumption depends on both gender and the drinking culture of the country of origin. ${ }^{3031}$

We found that the odds of having the metabolic pattern rose much more steeply with age in women. Before age 50 , metabolic syndrome is more common in men, but the reverse is true after age 50. The steeper age-related increase in metabolic syndrome in women is due to biological pathways involved in menopausal hormonal changes, as well as social and cultural factors influencing behaviour and response to stress. ${ }^{32}$ The higher prevalence of metabolic risk factors among Hmong women, with and without concurrent viral risk factors, was explained by their higher BMI.

The primary limitation of this study is that it is based on a convenience sample and may be subject to selection bias, with the potential for higher prevalence of $\mathrm{HBV}$ than in the overall Asian American population; however, a comparison with national data ${ }^{17}$ does not indicate that this is the case. Compared with foreign-born Sacramento County residents of the same ethnicity ${ }^{33}$ Chinese and Vietnamese participants tended to have immigrated more recently, which may have affected prevalence estimates of risk factors associated with length of residence. The gender-ethnicity sample sizes were rather small, especially for men, and the age distribution of our participants was quite different from that of the reference population so our standardised prevalence estimates had wide confidence intervals. In addition, the number of participants with the viral pattern was small relative to the number of parameters in model 2, which may have led to overfitting; nevertheless, the viral pattern odds ratios estimated by the two models were quite similar. We did not capture all known HCC risk factors, particularly serum lipids, and so were not able to assess metabolic syndrome. Because we did not measure the amount of alcohol consumed, participants could have the lifestyle pattern based solely on light drinking. However, it should be noted that there is some risk associated with the consumption of moderate amounts of alcohol, with a daily drink increasing the risk of liver cancer approximately $10 \% .{ }^{11}$ Nevertheless, the high prevalence of the lifestyle pattern among Vietnamese men should be interpreted cautiously. Finally, we did not measure alanine aminotransferase levels, and so could not assess the association between risk factors and liver damage.

To the best of our knowledge, TAAS is the first community-based study to include the concurrent collection of primary data on the prevalence of viral, metabolic, and lifestyle risk factors for HCC among foreign-born Chinese, Hmong, Korean and Vietnamese in a single county. Our findings showed that among foreign-born Asian Americans served by community organisations the occurrence of multiple HCC risk factors was not uncommon. Of the four risk factor patterns that we identified, two included the co-occurrence of risk factors in multiple domains. Those with the viral pattern, who had chronic hepatitis, were also likely to be at risk in the metabolic or, among men, lifestyle domains. Those with the lifestyle pattern, who were at risk due to alcohol use (or among men, smoking), were likely to have metabolic risk factors as well. Mitigating the progression to HCC through preventing chronic HBV infections for those who are not immune through vaccination and referral to care for infected individuals is the first step. ${ }^{34}$ Focused community-based interventions to address management of $\mathrm{HBV}$ and $\mathrm{HCV},{ }^{36}$ metabolic risk factors, ${ }^{37}$ alcohol, ${ }^{38}$ and tobacco ${ }^{39}$ have also had success; however, these approaches are not comprehensive. Community screening events, such as those attended by our participants, need to assess multiple risk factors, with referral to coordinated follow-up care as needed. The hierarchical risk factor patterns that we identified could be helpful in developing a checklist for case management. Culturally tailored interventions utilising collaborations between communities and healthcare providers are necessary to address multiple modifiable risk factors for HCC among populations-at-risk.

Acknowledgements We thank the community leaders and partner organizations that made this study possible: Aeyon Lee, Shalom Cancer Support Group; Kendra Thao and Youa Lo, Hmong Women's Heritage Association; Ruth Vinall, PhD, California Northstate University Cancer Awareness, Research, and Education student organization; Anh Le, Vietnamese Cancer Awareness Research \& Education Society (VN CARES); Ronald Jan, MD, Paul Hom Asian (Free) Clinic.

Contributors Conception and design: SLS, MSC; development of methodology: SLS; acquisition of data: JHTD, MSC; analysis and interpretation of data: SLS, MSC, JHTD, NJT; writing and review of the manuscript: MSC, JHTD, SLS, NJT; and study supervision: MSC.

Funding This work was supported through U51 PS0039441 from the Centers for Disease Control and Prevention, U54 CA153499 from the National Cancer Institute, the Francis Yee Fund for Cancer Disparities Research, the UC Davis Open Access Fund, and the Cancer Center Support Grant P30CA093373. However, the views in this paper are those of the authors.

Competing interests MSC served as a consultant to Gilead Sciences in 2016-18. Ethics approval Institutional Review Board at the University of California, Davis Provenance and peer review Not commissioned; externally peer reviewed. Data sharing statement № additional data are available.

Open access This is an open access article distributed in accordance with the Creative Commons Attribution Non Commercial (CC BY-NC 4.0) license, which permits others to distribute, remix, adapt, build upon this work non-commercially, and license their derivative works on different terms, provided the original work is properly cited, appropriate credit is given, any changes made indicated, and the use is non-commercial. See: http://creativecommons.org/licenses/by-nc/4.0/.

\section{REFERENCES}

1. Ferlay J, Soerjomataram I, Dikshit R, et al. Cancer incidence and mortality worldwide: sources, methods and major patterns in GLOBOCAN 2012. Int J Cancer 2015;136:E359-86.

2. Altekruse SF, Henley SJ, Cucinelli JE, et al. Changing hepatocellular carcinoma incidence and liver cancer mortality rates in the United States. Am J Gastroenterol 2014;109:542-53.

3. Fitzmaurice C, Dicker D, Pain A, et al. The global burden of cancer 2013. JAMA Oncol 2015;1:505-27. 
4. Dyson J, Jaques B, Chattopadyhay D, et al. Hepatocellular cancer: the impact of obesity, type 2 diabetes and a multidisciplinary team. $J$ Hepatol 2014;60:110-7.

5. Schütte K, Schulz C, Malfertheiner P. Nutrition and hepatocellular cancer. Gastrointest Tumors 2016;2:188-94.

6. Welzel TM, Graubard BI, Zeuzem S, et al. Metabolic syndrome increases the risk of primary liver cancer in the United States: a study in the SEER-Medicare database. Hepatology 2011:54:463-71.

7. Loomba R, Yang HI, Su J, et al. Synergism between obesity and alcohol in increasing the risk of hepatocellular carcinoma: a prospective cohort study. Am J Epidemiol 2013;177:333-42.

8. Calle EE, Rodriguez C, Walker-Thurmond K, et al. Overweight, obesity, and mortality from cancer in a prospectively studied cohort of U.S. adults. N Engl J Med 2003;348:1625-38.

9. Yuan JM, Govindarajan S, Arakawa K, et al. Synergism of alcohol, diabetes, and viral hepatitis on the risk of hepatocellular carcinoma in blacks and whites in the U.S. Cancer 2004;101:1009-17.

10. Koh WP, Robien K, Wang R, et al. Smoking as an independent risk factor for hepatocellular carcinoma: the Singapore Chinese Health Study. Br J Cancer 2011;105:1430-5.

11. Islami F, Miller KD, Siegel RL, et al. Disparities in liver cancer occurrence in the United States by race/ethnicity and state. CA Cancer J Clin 2017;67:273-89.

12. Bauer UE, Briss PA, Goodman RA, et al. Prevention of chronic disease in the 21st century: elimination of the leading preventable causes of premature death and disability in the USA. Lancet 2014;384:45-52.

13. Dang JH, Chen MS Jr. Increasing hepatitis B testing and linkage to care of foreign-born Asians, Sacramento, California, 2012-2013. Public Health Rep 2016;131(Suppl 2):119-24.

14. Stewart SL, Dang J, Chen MS Jr. Diabetes prevalence and risk factors in four Asian American communities. J Community Health 2016;41:1264-73.

15. Jih J, Mukherjea A, Vittinghoff E, et al. Using appropriate body mass index cut points for overweight and obesity among Asian Americans. Prev Med 2014;65:1-6.

16. Ryerson AB, Eheman CR, Altekruse SF, et al. Annual report to the nation on the status of cancer, 1975-2012, featuring the increasing incidence of liver cancer. Cancer 2016;122:1312-37.

17. Kowdley KV, Wang CC, Welch S, et al. Prevalence of chronic hepatitis $\mathrm{B}$ among foreign-born persons living in the United States by country of origin. Hepatology 2012;56:422-33.

18. Setiawan VW, Hernandez BY, Lu SC, et al. Diabetes and racial/ethnic differences in hepatocellular carcinoma risk: the multiethnic cohort. $J$ Natl Cancer Inst 2014;106:dju326

19. Lear SA, James PT, Ko GT, et al. Appropriateness of waist circumference and waist-to-hip ratio cutoffs for different ethnic groups. Eur J Clin Nutr 2010;64:42-61.

20. Ward $\mathrm{JH}$. Hierarchical grouping to optimize an objective function. $J$ Am Stat Assoc 1963;58:236-44.

21. United States Census Bureau: QuickFacts Sacramento County, CA. http://www.census.gov/quickfacts/table/PST045215/06067 (Accessed 15 Sep 2015).
22. Palaniappan LP, Wong EC, Shin JJ, et al. Asian Americans have greater prevalence of metabolic syndrome despite lower body mass index. Int J Obes (Lond) 2011;35:393-400.

23. Kutsenko A, Ladenheim MR, Kim N, et al. Increased prevalence of metabolic risk factors in Asian Americans with hepatocellular carcinoma. J Clin Gastroenterol 2017;51:384-90.

24. Khalili M, Lombardero $M$, Chung RT, et al. Diabetes and prediabetes in patients with hepatitis $B$ residing in North America. Hepatology 2015;62:1364-74.

25. Jarcuska P, Drazilova S, Fedacko J, et al. Association between hepatitis B and metabolic syndrome: Current state of the art. World $J$ Gastroenterol 2016;22:155-64.

26. Chan AW, Wong GL, Chan HY, et al. Concurrent fatty liver increases risk of hepatocellular carcinoma among patients with chronic hepatitis B. J Gastroenterol Hepatol 2017;32:667-76.

27. Balbi M, Donadon V, Ghersetti M, et al. Alcohol and HCV chronic infection are risk cofactors of type 2 diabetes mellitus for hepatocellular carcinoma in Italy. Int $J$ Environ Res Public Health 2010;7:1366-78

28. El-Serag HB. Epidemiology of viral hepatitis and hepatocellular carcinoma. Gastroenterology 2012;142:1264-73.

29. Choi S, Rankin S, Stewart A, et al. Effects of acculturation on smoking behavior in Asian Americans: a meta-analysis. J Cardiovasc Nurs 2008;23:67-73.

30. Cook WK, Caetano R. Ethnic drinking cultures, gender, and socioeconomic status in Asian American and Latino drinking. Alcohol Clin Exp Res 2014;38:3043-51.

31. Iwamoto DK, Kaya A, Grivel M, et al. Under-researched demographics: heavy episodic drinking and alcohol-related problems among Asian Americans. Alcohol Res 2016;38:17-25.

32. Pucci G, Alcidi R, Tap L, et al. Sex- and gender-related prevalence, cardiovascular risk and therapeutic approach in metabolic syndrome: A review of the literature. Pharmacol Res 2017;120:34-42.

33. U.S. Census Bureau, 2011-2015 American Community Survey 5-year Estimates. Table B05005; generated by Susan Stewart; using American FactFinder. 2018 https://factfinder.census.gov.

34. Chen MS Jr. Preventing Hepatitis B-induced liver cancer: implications for eliminating health disparities. J Health Dispar Res Pract 2010;4:88-99.

35. Chen MS Jr, Dang J. Hepatitis B among Asian Americans: prevalence, progress, and prospects for control. World J Gastroenterol 2015;21:11924-30.

36. Shah HA, Abu-Amara M. Education provides significant benefits to patients with hepatitis B virus or hepatitis $C$ virus infection: a systematic review. Clin Gastroenterol Hepatol 2013;11:922-33.

37. Sun Y, You W, Almeida F, et al. The effectiveness and cost of lifestyle interventions including nutrition education for diabetes prevention: a systematic review and meta-analysis. J Acad Nutr Diet 2017;117:404-21.

38. Toomey TL, Lenk KM. A review of environmental-based community interventions. Alcohol Res Health 2011;34:163-6.

39. Liao Y, Tsoh JY, Chen R, et al. Decreases in smoking prevalence in Asian communities served by the Racial and Ethnic Approaches to Community Health (REACH) project. Am J Public Health 2010;100:853-60. 